\title{
A STUDY OF SORPTION OF CADMIUM BY GOETHITE IN AQUEOUS SOLUTION
}

\author{
N. Salami* and F.A. Adekola \\ Department of Chemistry, University of Ilorin, P.M.B. 1515, Ilorin, Nigeria
}

(Received January 28, 2002; revised April 10, 2002)

\begin{abstract}
Investigation has been carried out on the potential of a locally sourced goethite for the removal of cadmium ion from aqueous solutions using batch equilibration technique. The maximum uptake of cadmium is $6.4 \times 10^{-2} \mathrm{mg} / \mathrm{g}$-goethite. The sorption kinetics appears to be rapid as equilibrium was attained within a period of 1 hour. The highest sorption capacity was obtained for particle size with diameter $(\phi) 0.09 \mathrm{~mm}$. Both infrared spectrophotometric and X-ray diffraction (XRD) techniques have also provided evidence for cadmium fixation on to the surface of the goethite. The sorption mechanism appears to follow Langmuir adsorption isotherm model. The Langmuir constants $\mathrm{K}$ and $\mathrm{X}_{\mathrm{m}}$ (mass of $\mathrm{Cd}^{2+}$ required to form monolayer on the entire surface of the goethite) were $0.096 \mathrm{mg} / \mathrm{g}$-goethite and $0.075 \mathrm{mg} / \mathrm{g}$-goethite, respectively.
\end{abstract}

KEY WORDS: Sorption of cadmium, Goethite, Sorption kinetics, Sorption mechanism, Langmuir adsorption isotherm

\section{INTRODUCTION}

Land and water, two basic resources of life, are increasingly stressed as a result of contamination resulting from increasing population growth, poor land and water use system, agricultural mechanization and industrialization [1]. The technological revolution led to sharp increased demand for water by industry and agriculture, and the same process led substantially to heavy pollution of surface and underground water [2]. The problem of wastewater on the composition of natural bodies of water is a major concern, since majority of inhabitants of land depends solely on treated wastewater as their drinking water. Throughout the world, there is significant rise in expenditures on measures to protect the environment from contaminants, particularly, hazardous waste [2]. Cadmium is one of the major heavy toxic elements, which may be found in both surface and underground water. The main sources of contamination are industrial wastes and phosphate fertilizers. One of the main toxic effects of cadmium resulting from its accumulation in the physiological system is an osseous disease producing similar symptom to osteoporosis [3].

Adsorption is a recognized method of removal of toxic elements in solution [4]. Adsorption of heavy metals on natural minerals and the ion-exchange properties of some natural minerals have been subjects of interest in the recent past [5,6]. The use of goethite could be a way of eliminating cadmium from polluted waters on industrial liquid waste. With the application of IR technique, both the crystalline and the X-ray amorphous samples can be employed for the investigation of the structure and mechanism of adsorption [7].

The objective of this work is to investigate the potential of a naturally occurring goethite mineral for the removal of cadmium ion from aqueous solution. In order to understand the sorption mechanism, we have used a multidisciplinary approach with several techniques such as batch sorption experiment, X-ray diffractometry and infrared spectrophotometry. 


\section{EXPERIMENTAL}

Materials. Identified $\alpha-\mathrm{FeO} . \mathrm{OH}$ (goethite) sample was obtained from Geological Survey Department of the Federal Ministry of Solid Mineral, Osogbo, Nigeria. The solid was reduced to fine particulate by grinding with the aid of mortal and pestle followed by sieving into various particle sizes of diameter, $\phi$, ranging between 0.09 and $0.5 \mathrm{~mm}$. That is $\phi<0.09,0.09<\phi<$ $0.25,0.25<\phi<0.4$ and $0.4<\phi<0.5 \mathrm{~mm}$.

All chemicals and reagents used were of Analar grades. Stock cadmium solution (100 ppm) was prepared by dissolving pure cadmium metal in concentrated $\mathrm{HNO}_{3}(70 \%)$. A series of cadmium standard solutions, ranging between 0 and $15 \mathrm{ppm}$, were then prepared. All measurements of cadmium concentrations were carried out with the aid of flame atomic absorption spectrophotometer (SP 9 AAS model coupled with a PM 8251 single pen recorder).

Cadmium sorption experiments. The cadmium nitrate $\left[\mathrm{Cd}\left(\mathrm{NO}_{3}\right)_{2}\right]$ salt was prepared by dissolving pure cadmium metal in concentrated $\mathrm{HNO}_{3}$. The resulting solution was gently heated to expel oxidized nitrogen from the solution. Standard cadmium solutions were prepared in 0.1 $\mathrm{M} \mathrm{CaCl}_{2}$ solution. Consequently, 0.05, 0.10, 0.20, 0.50, 1.0, 3.0, 5.0, 10.0, and $15.0 \mathrm{ppm}$ were prepared from stock solution. Fixation experiment was carried out using batch experiment technique. Each of the batch experiment was made up of $25.0 \mathrm{~cm}^{3}$ fractions of the various concentrations of cadmium ions (ppm) prepared and 1.0000 (!0.0002) g goethite. The resulting solutions were agitated on a motorized orbital shaker, Mk V orbital shaker, type Lh Fermentation, for $48 \mathrm{~h}-\mathrm{a}$ time sufficient enough for equilibrium to be attained. The $\mathrm{pH}$ of the supernatant solutions was measured before and after equilibration. All contact experiments were carried out in $0.1 \mathrm{M} \mathrm{CaCl}_{2}$ solution and a fairly stable $\mathrm{pH}$ of 6.5 !0.1 in order to maintain the ionic strength of the solution [5,8]. Fixation experiments were carried out in triplicates. The filtrates were analyzed by AAS for residual concentrations of cadmium ions left after equilibration [4]. Release of iron into solution was also monitored in order to ascertain the integrity of the goethite during contact experiment.

Sorption kinetics. This was carried out by varying the contact time from 2 min to $480 \mathrm{~min}(8 \mathrm{~h})$. The ratio of $\mathrm{Cd}^{2+}$ in solution to goethite, $0.15 \mathrm{mg} / \mathrm{g}$-goethite, was used throughout. This ratio corresponds to the optimum sorption capacity obtained from cadmium adsorption experiments.

Effect of particle size. The effect of particle size on the sorption capacity of goethite vis-a-vis cadmium was investigated using four different fractions ranging between $\phi(0.09-0.5) \mathrm{mm}$. That is $\phi<0.09,0.09<\phi<0.25,0.25<\phi<0.4$ and $0.4<\phi 0.5 \mathrm{~mm} .1 .0000 \mathrm{~g}$ of these was variously contacted with the same concentration of standard solutions of cadmium ions (6.0 ppm) in $0.1 \mathrm{M} \mathrm{CaCl}_{2}$ solution. The resulting solutions were agitated for a period of $8 \mathrm{~h}$ on a motorized orbital agitator; model $\mathrm{Mk} \mathrm{V}$ orbital shaker type Lh fermentation. The $\mathrm{pH}$ of the supernatant solutions was measured before and after the contact experiment. The filtrates were analyzed by atomic absorption spectrophotometer for cadmium ions remaining in solution.

Infrared spectroscopy. Infrared spectroscopic studies of the goethite before and after cadmium fixation were carried out. The infrared spectra were obtained on a Perkin Elmer 2000 model with an adjoined computer printer. A finely grinded goethite and thoroughly mixed with $\mathrm{KBr}$ pellet were used for this investigation.

XRD analysis. X-ray diffraction analysis was carried out using a Philips analytical X-ray B.V. diffractometer fitted with PC-APD diffraction software, a graphite monochromator and a $\mathrm{Cu}$ target X-ray tube operated at $40 \mathrm{kV}$ and $55 \mathrm{~mA}$. 


\section{RESULTS AND DISCUSSION}

Sorption of cadmium by goethite at a stabilized but slightly acidic medium, $\mathrm{pH}$ of about $6.5 ! 0.1$, were carried out. The analytical result of the filtrates for $\mathrm{Cd}^{2+}$ and $\mathrm{Fe}^{2+}$ shows that $\mathrm{Fe}^{2+}$ was practically not released into the solutions while $\mathrm{Cd}^{2+}$ were taken up by the solid goethite. This is an indication of the stability of goethite structure in the medium used, since $\mathrm{Fe}^{2+}$ was the major constituent cation in goethite [9].

Figure 1 illustrates the quantity of cadmium in $\mathrm{mg} / \mathrm{g}$-goethite as a function of the initial concentration of cadmium in $\mathrm{mg} / \mathrm{L}$. The linearized Langmuir adsorption isotherm of these data is shown in Figure 2. The linear nature of Langmuir isotherm suggests that the uptake of cadmium from solution is most likely to be by a physical means and not chemical. Figure 3 gives the quantity of cadmium adsorbed per gramme of goethite versus the contact time. This kinetic graph shows that $\mathrm{Cd}$ adsorption proceeds mainly through a one step, fast sorption kinetics as about $43 \%$ (which corresponds to maximum adsorption) of Cd was sorbed within 1 hour. The rate constant was found to be $4.58 \times 10^{-4} \mathrm{~min}^{-1}$.

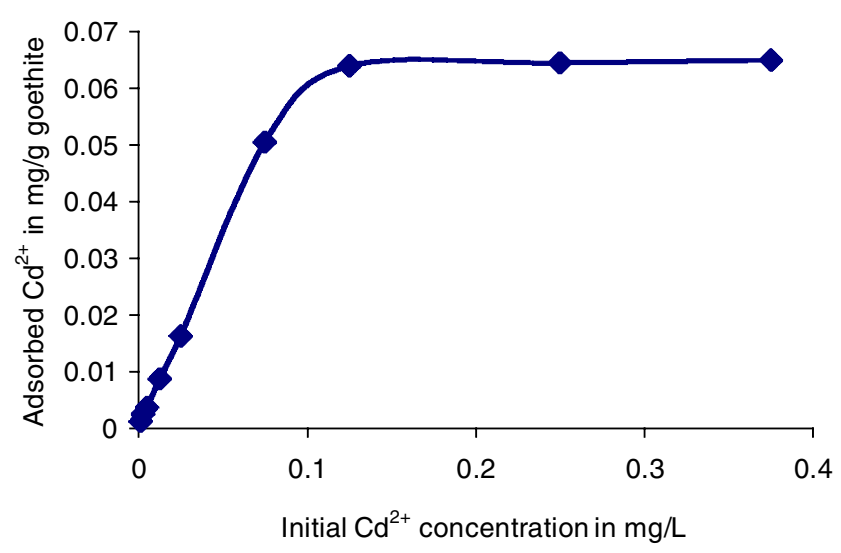

Figure 1. Adsorption of $\mathrm{Cd}^{2+}$ on goethite.

The results of experiment carried out on the effect of particle size as a function of cadmium ions uptake by goethite is summarised in Table 1 . It is observed that with decreasing particle size of goethite, there is non-linear increasing $\mathrm{Cd}^{2+}$ sorption by goethite. This could be attributed to the fact that surface area increases with decrease in particle size. This observation is in agreement with the result obtained by Jose et al. [7] who studied the effect of particle size of hematite mineral. Thus, the particle size with diameter $\phi<0.09 \mathrm{~mm}$, having the highest sorption capacity, was used for further 'batch experiment'. 


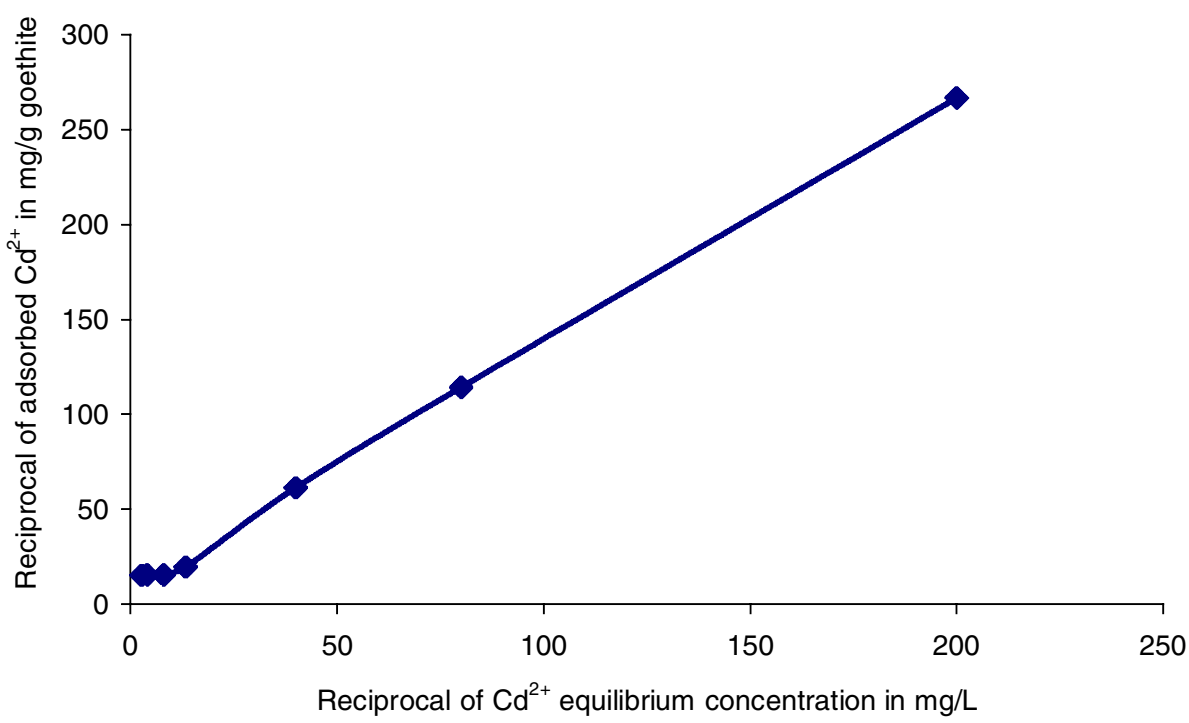

Figure 2. Langmuir adsorption isotherm for adsorption of $\mathrm{Cd}^{2+}$ on goethite.

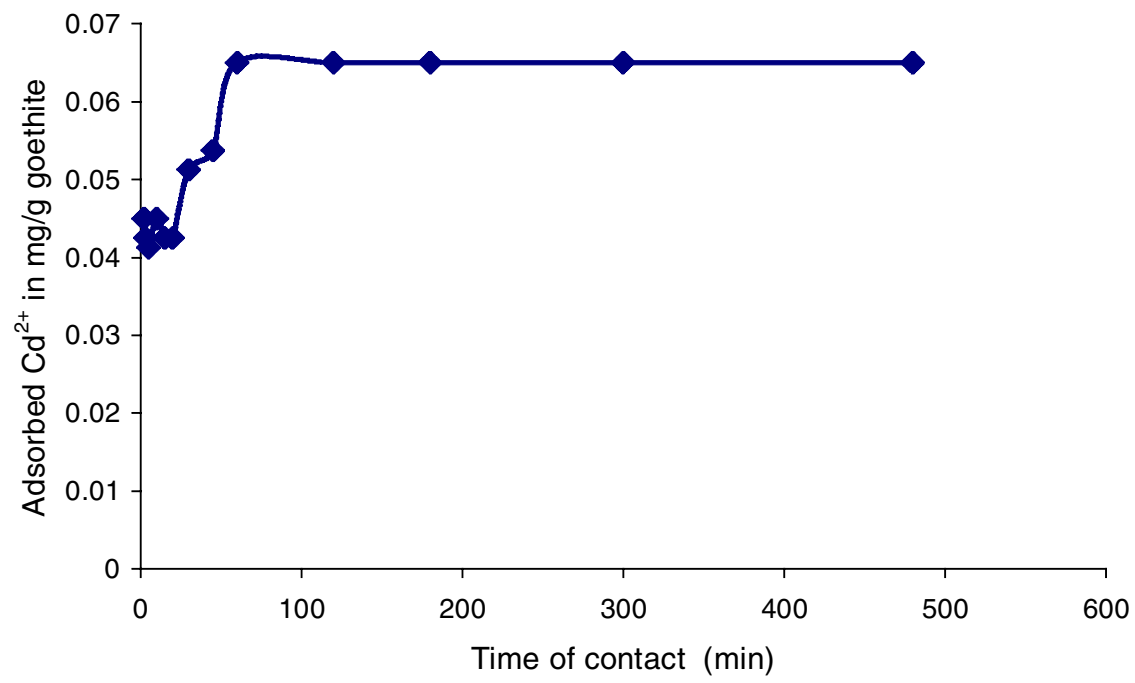

Figure 3. Kinetics of sorption of cadmium on goethite in aqueous solution.

Table 1. Effect of particle size on sorption of cadmium on goethite.

\begin{tabular}{|l|l|}
\hline Sample size $\phi(\mathrm{mm})$ & Adsorbed $\mathrm{Cd}^{2+}$ ions $(\mathrm{mg} / \mathrm{g})$ \\
\hline 0.09 & 0.00825 \\
\hline 0.25 & 0.00675 \\
\hline 0.4 & 0.005875 \\
\hline 0.5 & 0.005625 \\
\hline
\end{tabular}


The important infrared absorption frequencies of virgin goethite and Cd-goethite as recorded by IR are summarized in Tables 2 and 3, respectively. The assignments of the frequencies were made in accordance with Nakamato [10] and Saheed et al. [11]. The IR spectrum of a powdered sample varies depending on its particle size and shape [7]. The same particle size of diameter $\phi<$ $0.09 \mathrm{~mm}$ was used throughout the experiments, so that the IR spectra of the natural goethite and its Cd-sorbed goethite can be compared. The $\mathrm{Fe}-\mathrm{OH}_{2}$ bonded frequency [5] 700, 791, and 919 $\mathrm{cm}^{-1}$ was slightly shifted in Cd-goethite. Similar slight shifts were observed for $\mathrm{O}-\mathrm{H}$ stretching and bending frequencies from 3685 to $3679 \mathrm{~cm}^{-1}$ and 1284 to $1320 \mathrm{~cm}^{-1}$, respectively. The absorption band at $3612 \mathrm{~cm}^{-1}$ for raw and Cd-goethite is assigned to relatively free surface $\mathrm{OH}$ groups similar to what was reported by Russel [12], $3615 \mathrm{~cm}^{-1}$, for partially dried goethite. The residual absorption band $1673 \mathrm{~cm}^{-1}$ is assigned to $\mathrm{HOH}$ of water or intermolecular water [10, 12]. Two new IR spectra bands appeared at 1727 and $1837 \mathrm{~cm}^{-1}$ in the Cd-goethite and they could be associated with $\mathrm{Cd}-\mathrm{OH}$.

Table 2. Frequencies of IR absorption bands and their assignments for natural goethite.

\begin{tabular}{|l|l|}
\hline Frequency ${ }^{*}\left(\mathrm{~cm}^{-1}\right)$ & Assignments \\
\hline $700 \mathrm{~s}, 797 \mathrm{~s}, 919 \mathrm{~s}$ & $\mathrm{Fe}-\mathrm{OH}_{2}$ stretching frequencies \\
\hline $1047 \mathrm{~s}, 1119 \mathrm{~m}$ & $\mathrm{Fe}-\mathrm{O}$ asymmetric stretching frequencies \\
\hline $1284 \mathrm{w}, 1466 \mathrm{w}$ & $\mathrm{O}-\mathrm{H}$ bending frequency \\
\hline $1539 \mathrm{~m}, 1673 \mathrm{w}$ & $\delta(\mathrm{HOH}), \mathrm{H}_{2} \mathrm{O}$ of crystallization \\
\hline $2348 \mathrm{w}, 2925 \mathrm{w}$ & Intramolecular $\mathrm{H}-\mathrm{OH}$ frequencies [10] \\
\hline $3126 \mathrm{w}, 3612 \mathrm{~m}$ & Intermolecular and weakly bonded $\mathrm{O}-\mathrm{H}$ frequencies \\
\hline $3685 \mathrm{~m}$ & $\mathrm{v}(\mathrm{O}-\mathrm{H})$ stretching vibration. \\
\hline $3782 \mathrm{w}, 3874 \mathrm{w}$ & $\mathrm{v}(\mathrm{HOH})$, water of crystallization stretching frequencies \\
\hline
\end{tabular}

*Intensity: $\mathrm{s}=$ strong, $\mathrm{m}=$ medium, $\mathrm{w}=$ weak.

Table 3. Frequencies of IR absorption bands and their assignments for Cd-adsorbed goethite.

\begin{tabular}{|l|l|}
\hline Frequency ${ }^{*}\left(\mathrm{~cm}^{-1}\right)$ & Assignments \\
\hline $694 \mathrm{~m}, 797 \mathrm{~s}, 925 \mathrm{~s}$ & $\mathrm{Fe}-\mathrm{OH}_{2}$ stretching frequencies \\
\hline $1044 \mathrm{~s}, 1320 \mathrm{~m}$ & $\mathrm{O}-\mathrm{H}$ bending frequencies \\
\hline $1466 \mathrm{w}, 1648 \mathrm{w}$ & $\delta(\mathrm{HOH}), \mathrm{H}_{2} \mathrm{O}$ of crystallization \\
\hline $1727 \mathrm{sh}, 1837 \mathrm{sh}$ & $\mathrm{v}(\mathrm{Cd}-\mathrm{Fe})$ stretching frequencies \\
\hline $3612 \mathrm{w}$ & Intermolecular and weakly bonded $\mathrm{O}-\mathrm{H}$ \\
\hline $3679 \mathrm{~m}$ & $\mathrm{v}(\mathrm{O}-\mathrm{H})$ stretching frequencies. \\
\hline $3819 \mathrm{w}$ & $\mathrm{v}(\mathrm{HOH}), \mathrm{H}_{2} \mathrm{O}$ of crystallization. \\
\hline
\end{tabular}

*Intensity: $\mathrm{s}=$ strong; $\mathrm{m}=$ medium, $\mathrm{w}=$ weak; $\mathrm{sh}=$ shoulder.

The results of X-ray diffractometry analysis for raw goethite and Cd-goethite were illustrated in Figures 4 and 5, respectively. There are 29 and 31 distinct peaks patterns for raw and Cdgoethite, respectively. Characteristic peaks for raw goethite were observed for angle, $2 \theta$, at 18.20 (18), 21.155 (21), 33.42 (34), and 37.19 (37) with corresponding d-value for $\alpha_{1}(\mathrm{X})$ at 4.8703 (4.98), 4.1962 (4.18), 2.679 (2.69) and 2.4156 (2.45), respectively. All values within the brackets are similar values obtained in literature [13] for goethite materials. All these peaks were equally observed for Cd-goethite but slightly shifted. 


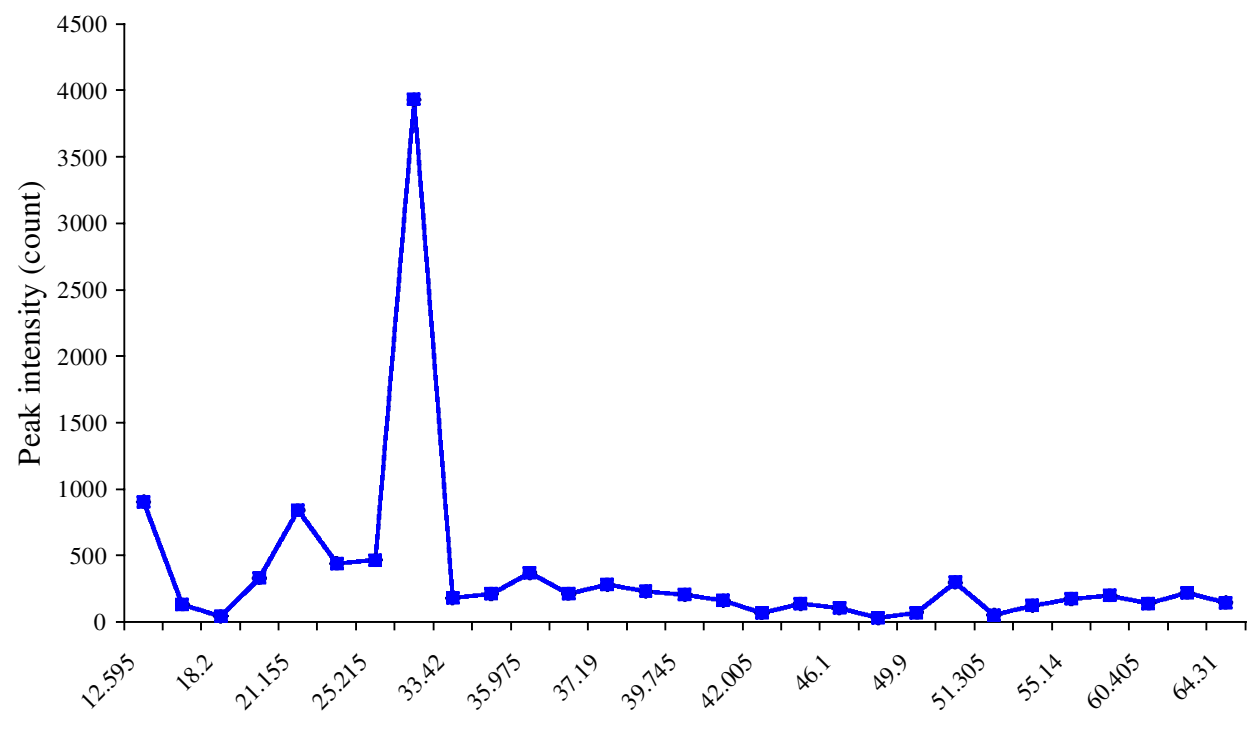

Angle (20)

Figure 4. X-ray diffraction patterns of powder sample of natural goethite.

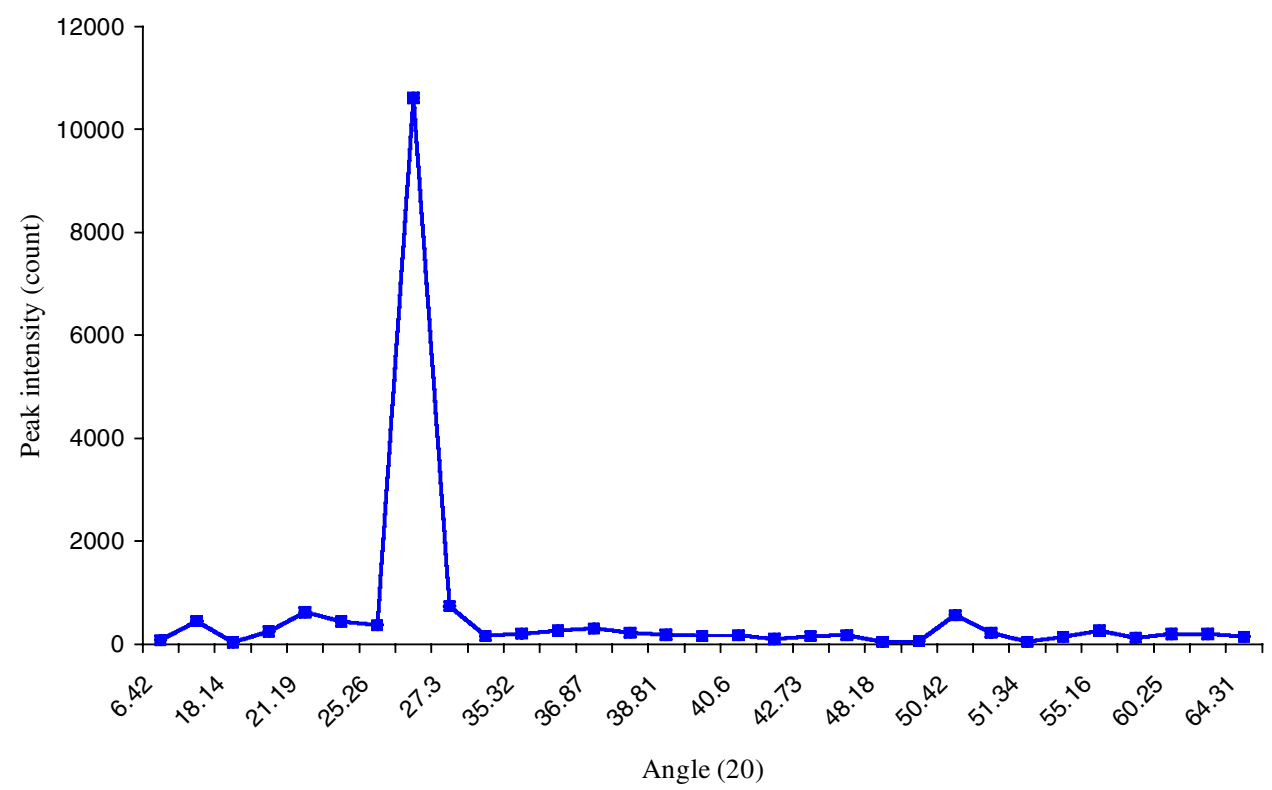

Figure 5. X-ray diffraction patteerns of powder sample of $\mathrm{Cd}^{2+}$ sorbed-goethite. 
There are two essential new peaks in Cd-goethite appearing for angle $2 \theta$ at 27.295 and 55.945 with corresponding $\mathrm{d}$-value for $\alpha_{1}(\mathrm{X})$ at 3.2646 and 1.6422 , respectively. These are attributed to the presence of $\mathrm{Cd}$ in the structural lattice of goethite.

The presence of other peaks pattern is a probable indication that the sample material is a mixture of Fe-ore but predominantly goethite in abundance ratio when peaks originating from

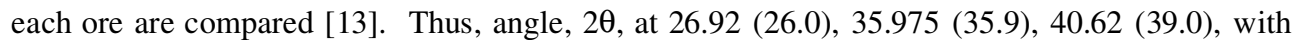
corresponding d-value for $\alpha(\AA) \quad 3.3092$ (3.66), 2.4944 (2.51), and 2.2192 (2.201) are characteristics of hematite. All values within brackets are literature values [13].

\section{CONCLUSION}

Sorption of cadmium ions on to the goethite appears to be governed by Langmuir adsorption isotherm. It proceeds through a physical adsorption on to the goethite surface. The adsorbed cadmium ion concentration is a function of surface of goethite available for contact reaction.

The retention of XRD peak patterns in Cd-goethite lends support to retention of the goethite structural lattice when $\mathrm{Cd}$ is sorbed on it. This is in agreement with the analysis of Cd-sorption experiment, which shows non-release of Fe. Consequently, it could be concluded that goethite structure did not collapse under these experimental conditions. This is a good characteristic for an eventual industrial application. Further work in this regard is in progress in our laboratory. We are presently investigating the influence of certain organic compounds, cations and anions (that could be coexisting with $\mathrm{Cd}^{2+}$ ) on the sorption capacity of the goethite.

\section{REFERENCES}

1. Ibe, K.M.; Sowa, A.H.O; Osondu, O.C. Nigerian J. Min. Geol. 1992, 28, 87.

2. Dedkov, Yu. M. Zh. Anal. Khim. 1987, 42, 1675.

3. Jeanjean, J; Fedoroff, M.; Faverjon, F; Vincent, U. J. Mater. Sci. 1996, 31, 6156.

4. Kapoor, A; Viraraghavan, T. J. Environ. Eng-ASCE. 1998, 124, 1020.

5. Egozy Y. Clays Clay Minerals 1980, 28, 311.

6. Ferrel, R.E. Jr.; Prince, C.A. Clays Clay Minerals 1978, 26, 41.

7. Rendon, J.L.; Serna, C.J. Clay Miner. 1981, 16, 375.

8. Hante, G. Van; Delmon, B. Chem. Inorg. Tech. 1978, 48, 856.

9. Bailey, S.W. International Clay Conference, Applied Publishing Ltd.: Wilmette, Illinois; 1975; p 601.

10. Nakamato, K. Infrared Spectra of Inorganic and Coordination Compounds, 3rd ed., Wiley: New York; 1978, p 239.

11. EL-Sayeed, M.F.A.; Sheline, R.K. J. Inorg. Nucl. Chem. 1958, 6, 187.

12. Russell, J.D. Clay Miner. 1979, 14, 109.

13. Shadfan, H.; Dixon, J.B.; Calhoun, F.G. Soil Sci. 1985, 140, 317. 